\title{
Ações e Políticas Públicas de Inclusão Digital: do global ao local, através de conceitos e processos educacionais
}

\author{
Nadja da Nóbrega Rodrigues ${ }^{1}$, Mércia Rejane Rangel Batista ${ }^{2}$ \\ ${ }^{1}$ Unidade Acadêmica de Informática \\ Instituto Federal da Paraíba (IFPB) - João Pessoa, PB - Brasil \\ ${ }^{2}$ Unidade Acadêmica de Ciências Sociais \\ Universidade Federal de Campina Grande (UFCG) - Campina Grande, PB - Brasil. \\ nadja.rodrigues@ifpb.edu.br, mercia.batistal@gmail.com
}

\begin{abstract}
This article presents partial results of a research that interprets the relationships between Digital Inclusion (ID) and the promotion of citizenship and social inclusion, mainly approaching the insertion of ICDT in educational processes. In his prevailing discourse, ID favors emancipation and social inclusion. The investigation of the public policy and actions of ID in IFPB suggests efforts that attempt to align themselves to this discourse, however, the gap between included and excluded goes beyond the access to and manipulation of technologies. Should also be considered factors such as the cognitive aspects of the use of ICDT, the educational processes and the development of knowledge on how to appropriate of them as a citizen.
\end{abstract}

Resumo. Este artigo apresenta resultados parciais de uma pesquisa que interpreta as relações entre a Inclusão Digital (ID) e a promoção da cidadania e da inclusão social, abordando, principalmente, a inserção de TDIC em processos educacionais. Em seu discurso predominante, a ID favorece emancipação e inclusão social. A investigação da política pública e de ações de ID no IFPB sugere esforços que tentam se alinhar a esse discurso, entretanto, a fenda entre incluídos e excluídos vai além do acesso e manuseio de tecnologias. Também devem ser considerados fatores como os aspectos cognitivos de uso das TDIC, os processos educacionais e o desenvolvimento de conhecimento sobre como se apropriar delas, enquanto cidadão.

\section{Introdução}

O mundo contemporâneo traz, como um de seus grandes conceitos, as redes sociais. Mas o que significa viver as redes modernas? "Redes sociais são, antes de tudo, redes de comunicação que envolvem linguagem simbólica, restrições culturais, relações de poder" (CAPRA, 2008, p.22). Ao pensar em redes, o senso comum sugere que o mundo inteiro está conectado, e que as pessoas trafegam de um extremo ao outro, nessas plataformas, conectadas de forma "ponto a ponto". Entretanto, nessa rede, há fendas que dão origem à "exclusão digital", que traz, em sua essência, um problema recorrente em sociedades desiguais, a exclusão social, que se apresenta através de particularidades distintas, mas continua tendo como base a negação de direitos e da cidadania.

No Século XXI, período em que as informações crescem exponencialmente a partir das mídias digitais e o conhecimento tem lugar de destaque nas rotinas humanas, 
VII Congresso Brasileiro de Informática na Educação (CBIE 2018)

Anais do XXIV Workshop de Informática na Escola (WIE 2018)

as reivindicações do "acesso para todos" significam que a participação nesse espaço assinala um direito, entretanto, a universalidade passa a depender de questões políticas e técnicas, que limitam pessoas, pela falta de acesso às Tecnologias Digitais de Informação e Comunicação (TDIC), ou pela subutilização desses recursos, em termos de qualificação para ação social. "A área 'Coberta' por qualquer rede é 'universal', mas apenas onde existem suficientes antenas, relés, repetidores, e assim por diante" (LATOUR, 2011, tradução nossa). Nesse cenário, acessar os microcontextos evita simplificar realidades através de generalizações que ignorem aspectos de desigualdade e segregação.

Em qualquer escopo (país, estado ou município), a sociedade brasileira parece ser composta por inúmeros "mundos" próprios. Em termos de ausências, fendas podem ser percebidas em temas centrais como acesso a educação e saúde, participação política, condição econômica, e assim, reflexões sobre esses temas levam a disparidades e assimetrias. Como então governar essa sociedade e construir ações e políticas públicas para promover a inclusão? O discurso dominante relaciona as TDIC à ideia de inclusão e, portanto, a ausência dos aparatos materiais nos processos de promoção do desenvolvimento cognitivo e do conhecimento, e das ações sociais, representa o "analfabetismo digital", a exclusão social contemporânea. "São milhões de brasileiros que nunca utilizaram a internet ou mesmo um computador, e assim permanecem afastados de novas oportunidades de trabalho, novos conteúdos culturais, bem como de novas formas de exercer a cidadania" (BRASIL, 2015, p. 15).

Qual a implicação desse cenário para a vida contemporânea? Giddens (1991) já chamava a atenção para mudanças que acompanhavam a implantação das TDIC. O ciberespaço pode ser pensado como o meio de comunicação aberto que surge com a internet e suas possibilidades de interconexão, referindo-se menos à infraestrutura material, e mais às informações que ela abriga e aos seres humanos que navegam e alimentam esse espaço (Martino, 2015). Já a cibercultura especifica o conjunto de técnicas, práticas, modos de pensamento e valores que se desenvolvem juntamente com o ciberespaço, e compõem um sistema organizado em função do complexo tecnológico e dos novos processos comunicativos (Lévy, 1999; Ferreira, 2016). Ressalta-se que a trajetória humana traz juntamente às técnicas e aos instrumentos, um conjunto de aspectos subjetivos, o que implica em colocá-los em dimensões humanas, no esforço de repensar a vida em coletividades. Segundo Martino (2015), as relações através das mídias digitais alteram o que se entende por política, arte, economia e cultura, o que reforça a multidimensionalidade das TDIC. Através dessas tecnologias, processos sociais são desenvolvidos mesclando o mundo físico e o virtual, e então, a exclusão digital potencializa a exclusão social.

A Inclusão Digital (ID) visa o planejamento e a execução de ações com o objetivo de permitir a participação de todos na sociedade da informação (Rodrigues et al., 2011). No Brasil, a política pública de ID evidencia temas como cidadania, inclusão social, desenvolvimento local e nacional, em três eixos fundamentais: garantia de acesso às TDIC; incentivo à disponibilização de conteúdos de interesse público; capacitação da população e dos profissionais que atuam no atendimento ao cidadão. Nesses eixos, um dos grandes desafios é desenvolver processos que permitam desde os primeiros contatos com as TDIC, até a apropriação dessas tecnologias para execução das diversas rotinas sociais, o autodesenvolvimento humano e a inteligência coletiva em rede. Em outras palavras, os processos educacionais, de qualificação e de desenvolvimento do conhecimento influenciam as TDIC e são influenciados por elas. 
VII Congresso Brasileiro de Informática na Educação (CBIE 2018)

Anais do XXIV Workshop de Informática na Escola (WIE 2018)

Na passagem para esse século, as previsões diziam que escolas e universidades seriam as instituições menos afetadas pela lógica virtual embutida na TDIC, pois mesmo com o uso quase universal de computadores em salas de aula, essas instituições não desapareceriam do espaço físico, devido às suas funções estruturais e particularidades de funcionamento (Castells, 2000). Nos dias de hoje, o que se percebe: em grande parte, as funções educacionais ainda estão associadas à interação pessoal; escolas de ensino fundamental e médio, além das funções educacionais, ainda são "repositórios de crianças" (tendo surgido também os berçários); embora a Educação à Distância (EAD) esteja aliada àquela presencial, esta não é eliminada ou superada pela EAD. Por outro lado, algumas mudanças previstas podem ser percebidas (Lévy, 1999): o que é preciso aprender não pode ser precisamente definido com antecedência; perfis de competência podem cada vez menos ser canalizados em cursos generalizadores; informações e conhecimentos estão distribuídos na rede, atualizando-se em tempo real; a nova natureza do trabalho requer aprender, transmitir saberes e produzir conhecimento, em um ciclo contínuo; tecnologias intelectuais modificam funções cognitivas humanas, favorecendo novas formas de acesso à informação, estilos de raciocínio e de conhecimento; como essas tecnologias são objetivadas em elementos disponíveis na rede, elas podem ser compartilhadas, potencializando a inteligência coletiva dos grupos humanos, ou seja, o conhecimento produzido de maneira social.

Esse cenário sugere novos modelos de espaço de conhecimentos, abertos, contínuos e em fluxo, de acordo com contextos, nos quais cada um ocupa uma posição singular. Enxergar os desafios colocados pela cibercultura, aos processos educacionais, significa pensar nas TDIC enquanto parte de um projeto maior, que fundamenta suas discussões nas relações entre seres humanos, conhecimentos e ações, considerando as possibilidades técnicas trazidas pelas tecnologias. A grande questão que a cibercultura põe à educação e ao conhecimento, não é nem tanto a passagem do presencial à distância, do escrito/oral à multimídia, mas a transição de uma educação estritamente institucionalizada (a escola, a universidade) para a troca generalizada de saberes, o ensino da sociedade por ela mesma, de reconhecimento contextual das competências, sendo cada conhecimento valorizado em seu contexto específico, sem implicar na desqualificação dos outros, o que promove a equiparação entre os tipos de saberes e dispensa categorias distintas - cultura universitária x cultura popular, escola x mercado (Lévy, 1999; Martino, 2015).

Em outras palavras, a busca da efetividade nas ações educacionais considera importante o contexto social no processo educacional (Santiago et al., 2016), e a necessidade, no contexto, é a medida do valor dos conhecimentos. É o sentido da atuação humana nas plataformas técnicas que faz a diferença: é saber "o que fazer" e "como fazer" em termos cívicos que evidencia os benefícios do ciberespaço e orienta o percurso dos cibercidadãos.

Sobre os trabalhos em ID, pesquisadores consideram o tema atual e relevante, uma vez que a ID ganhou espaço como política governamental nas últimas décadas, e sugerem que, no Brasil, o seu processo de avaliação está incipiente, na academia e no governo (Corrêa, 2007; Mattos; Chagas, 2008; Medeiros Neto; Miranda, 2010; Rodrigues; Maculan, 2013). Este artigo apresenta resultados de uma pesquisa em andamento, e se propõe a retratar aspectos referentes a ações e à política pública de ID no Brasil, e assim contribuir para a compreensão das relações entre ID, cidadania e inclusão social, principalmente sob perspectivas educacionais, envolvendo discursos e ações de ID dos governos federal (GF), da Paraíba (GE) e de João Pessoa (GM), e um estudo de caso no IFPB. 
VII Congresso Brasileiro de Informática na Educação (CBIE 2018)

Anais do XXIV Workshop de Informática na Escola (WIE 2018)

\section{Métodos}

A pesquisa faz parte de um processo de doutoramento na UFCG, desde 2014, envolvendo pesquisa e extensão nesta instituição e no IFPB, e algumas atividades: revisão teórica; mapeamento da política pública de ID e de políticas e iniciativas de extensão de ID no IFPB; análise das relações entre esses elementos e das suas contribuições à cidadania e à inclusão social. Tem caráter exploratório e descritivo, investigando e relacionando variáveis como TDIC, ID, cidadania e inclusão social. Como procedimentos técnicos, inclui participação em eventos, investigação nos portais de governo e estudo de caso no IFPB, com base na etnografia, a partir de levantamento de dados, análise documental e processual. Como instrumentos de coleta de dados, usa formulários, observação sistemática e diário de campo. As principais fontes de dados são documentos, páginas web, dados de entrevistas, de conversas informais e de observação participante. As entrevistas usam história oral, registrando a experiência de indivíduos no IFPB, recobrindo relatos a respeito de fatos não registrados por outros documentos (Queiroz, 1988). A abordagem é qualiquantitativa, definindo indicadores e interpretando dados com base nas evidências contextuais. O campo empírico é composto pelos governos e pelo IFPB; como lócus de pesquisa, mapeiam-se portais dos governos e espaços ligados à extensão do IFPB.

Sobre o estudo etnográfico, baseia-se em um escopo mais generalista que aborda o Brasil, e em microinvestigações locais, na Paraíba e em João Pessoa. Perlongher (2008) sugere alguns aspectos da antropologia urbana: nas cidades, o "território único" será substituído pela plurilocalidade das sociedades complexas; não se pode impor uma exigência de homogeneidade do grupo observado; a importância do "grupo" é diminuída, em favor das microredes relacionais; as relações interpessoais constituem a unidade local; a pesquisa centra-se no nível micro, que reproduz ou resiste à ordem social dominante; não há uma relação de causalidade fixada com antecedência entre o macro e o micro, mas uma tensão contínua; não é pertinente considerar o campo empírico como plano de constatação de hipóteses, mas local de experimentação conceitual. O trabalho de campo vem sendo realizado desde 2015, através da participação em evento internacional (Fórum de Governança da Internet - IGF) e outros nacionais (reuniões da Associação Nacional de Inclusão Digital - ANID); coleta de notícias e indicadores referentes a ID nos portais do GF, GE e GM, na internet; ações de pesquisa e extensão no IFPB. A conexão entre o macro e o microestudos vem sendo pensada através da análise do contexto processual da política nacional de ID (relações entre GF, GE e GM), no período de 2007 a 2017, e se/como os governos influenciaram a extensão do IFPB (este executando ações junto a indivíduos, que foram, ou deveriam ter sido, beneficiários de ações de governos). A partir de situações sociais particulares, podem-se abstrair elementos importantes (Foote-Whyte, 2005), sendo possível enxergar, em meio à diversidade de contextos, a validade de generalizações. No IFPB já foi realizado o levantamento da política de extensão, entrevistas (três monitores e dezessete alunos de cursos de extensão), conversas formais/informais (onze técnicos e (ex) gestores de extensão, quatro monitores e mais de cem representantes comunitários em atividades de extensão), observação participante em dois programas de extensão (P1 e P2). Nos portais do GF, GE e GM, foi feita a coleta de dados sobre a política pública de ID (mais de 800 páginas web). Algumas análises quali-quantitativa dos dados de governo e IFPB já foram realizadas. Essa pesquisa protege a identidade dos pesquisados.

\section{Resultados e Discussão}

As ações oficiais em campo tiveram início em 2015, nos eventos, nos portais e no IFPB. Em termos de discussões internacionais sobre a relação entre desenvolvimento humano 
VII Congresso Brasileiro de Informática na Educação (CBIE 2018)

Anais do XXIV Workshop de Informática na Escola (WIE 2018)

e TDIC, e a inclusão das pessoas nos processos de governança da internet e no ciclo de políticas públicas de ID, o IGF foi um momento importante para ter acesso a esses discursos e vivenciar algumas de suas realizações em campo empírico. Os governos enfatizaram a ideia de construção de uma internet global, baseada em multilateralismo e multissetorialismo, em articulações entre países, setores e grupos sociais, trazendo a participação política como elemento imprescindível para as definições democráticas, requerendo a revisão do conceito de cidadania, e das relações entre os agentes sociais. Os modelos brasileiros de governança da internet, Marco Civil e de política pública de ID eram referências a ser seguidas pelo mundo, uma vez que evidenciavam que "o acesso à internet é essencial ao exercício da cidadania" e que o país tinha feito "grandes esforços para promover o acesso à internet para todos".

Os discursos nos portais dos governos mostraram o avanço da política pública de ID, o "crescimento econômico, aumento da produtividade, integração nacional e acima de tudo, inclusão digital e social da população". Apesar do estereótipo de "lugares pobres e atrasados", a Paraíba e João Pessoa, foram apresentadas como territórios onde as gestões públicas se destacaram, investindo em ações de ID e de construção de uma gestão democrática e participativa, da inovação no uso de TDIC. Dados de uso da internet na Paraíba indicaram taxas maiores do que aquelas em "estados economicamente mais fortes", entretanto, ações propostas pelo GF se relacionaram diretamente com governos municipais e, então, não se deve achar que toda a Paraíba se desenvolveu em ID na mesma velocidade que João Pessoa o fez (sendo esta referência em ID, ao nível de Brasil).

Os dados do GF, GE e GM sugeriram as tentativas de cobrir todos os seus territórios com ações, a dinamicidade do conceito de ID e o desenvolvimento de políticas multidimensionais, mas seus microindicadores refletiram a persistência da exclusão em comunidades e lugares particulares. Alguns espaços sociais, visitados no trabalho em campo, levaram à percepção sobre a presença ou ausência dos benefícios advindos das TDIC, e problemas ainda mais específicos, como a longa espera pela mudança de cabeamento de rede para conectar computadores de uma escola pública à internet. Esses dados reforçaram a importância dos microindicadores, rejeitando discursos generalizantes enquanto termômetros das políticas públicas. Outros indicadores dos governos informaram que, apesar da crescente penetração da rede, esse indicador ainda era superado pelo número de pessoas offline. Então, era preciso que a internet fizesse a diferença na vida de todos, em saúde, educação, emprego e segurança, reduzisse a discriminação e as desigualdades, com frutos distribuídos de forma justa.

Dados específicos sugeriram a inserção das TDIC nos processos educacionais e qualificação de diversos grupos sociais para uso de TDIC, e algumas relações entre ID, cidadania e inclusão social. Entre 2007 e 2017, mais de cem páginas web noticiaram ações de ID dos governos relacionadas a questões educacionais, desenvolvidas em várias dimensões: debate com a sociedade sobre ações educacionais (incluindo TDIC); informatização nas escolas públicas; distribuição de notebooks e tablets entre professores e alunos da rede pública; desenvolvimento de tecnologias educacionais, de escolas em tempo integral com oficinas de ID e de programas educacionais com ações específicas em ID. Essas ações se ligaram à política de ID, principalmente através do Banda Larga nas Escolas (conectava escolas públicas à internet), Programa Um Computador por Aluno - Prouca (promovia a adoção de TDIC nas escolas públicas por 
VII Congresso Brasileiro de Informática na Educação (CBIE 2018)

Anais do XXIV Workshop de Informática na Escola (WIE 2018)

meio da distribuição de computadores portáteis aos alunos) e ProInfo Integrado (promovia o uso pedagógico da informática na rede pública, articulando distribuição de equipamentos e capacitação de professores, técnicos, gestores e agentes educacionais). Sobre as ações do GF, as principais considerações podem ser vistas no Quadro 1.

\section{Quadro 1. Ações de ID do GF na perspectiva da educação}

Ações ligadas à política educacional, Banda Larga nas Escolas, Prouca, ProInfo Integrado

Em termos de políticas nacionais, as ações de ID representaram parte de diversos programas na educação, estes trazendo não apenas a formação escolar, mas também a preocupação com trabalho e renda, integração social e cidadania, em territórios urbanos ou rurais, o que sugeriu a interdisciplinaridade nas ações de ID.

O GF investiu em infraestrutura, mas ressaltou a importância da capacitação de professores e alunos. Além de serem vistas como imprescindíveis diante das reconfigurações culturais nas sociedades modernas, as tecnologias eram elementos motivacionais nos processos educativos, que apresentavam indicadores a ser melhorados, como aqueles do ensino médio, considerado o "nó" da educação brasileira.

Para o GF, o Brasil podia viver o sentimento de integração (indicadores apontavam mudanças importantes, como diminuição da pobreza multidimensional e desigualdades), e a educação tinha um papel importante para o futuro do país. A sociedade foi convidada a construir um grande movimento em prol dessas perspectivas, o que sugeriu abertura para construção de um governo participativo. Em termos de ação, foi identificada a participação de representantes da sociedade civil, como movimentos sociais, na construção de ações de ID e dos conceitos de cultura digital, sugerindo a importância da comunidade no ciclo da política pública de ID.

O GF motivou a realização de ações de extensão com foco em ID, por instituições de ensino. Uma vez que a extensão aproxima essas instituições da comunidade, a ação do GF representou um direcionamento para o fortalecimento da realização de suas ações junto a essas comunidades.

Entre os programas, projetos e ações de ID propriamente ditos, a proposta do GF foi que essas iniciativas de alguma forma se conectassem entre si, como exemplo, a oferta de infraestrutura em TDIC, à qualificação através de cursos nessas tecnologias e à produção de conteúdos que poderiam ser utilizados em sala, o que sugeriu a preocupação com várias perspectivas de desenvolvimento da ID nos espaços educacionais.

Sobre os beneficiários das ações, o portal apresentou seus discursos, sugerindo que a sociedade reconhece a "necessidade" de apropriação das TDIC para mudança na cultura, nova "mentalidade" e novos hábitos.

As ações educacionais revelaram uma teia de agentes que precisavam garantir a infraestrutura de máquinas, internet, softwares educacionais e ainda as habilidades para autodesenvolvimento e continuidade de ações.

Entre os resultados identificados, em termos qualitativos, o GF evidenciou o "desenvolvimento do Nordeste", como resultado do avanço do sistema educacional.

Para o GF, a distribuição dos computadores nas escolas, através do Prouca, ia além do consumo de equipamentos, disseminando a infraestrutura privada enquanto democratização das TDIC junto a pessoas de baixo poder aquisitivo, e estimulando o uso dessas tecnologias de forma aplicada às estratégias educacionais.

No Prouca e nas demais ações, as questões educacionais voltadas ao campo, a comunidades indígenas e quilombolas, envolveram a educação contextualizada, a conexão entre disciplinas curriculares e contexto social dessas comunidades, algo importante para a efetividade da ID, conforme percebido no estudo no IFPB.

Sobre os beneficiários das ações, os seus discursos sugerem que a distribuição de tablets deslocou o uso das TDIC de ambientes institucionais formais, incorporando essas tecnologias em várias dimensões de suas vidas.

Buscando as relações entre a política nacional e ações locais, foram identificados desdobramentos das ações federais em iniciativas estaduais e municipais. Sobre ações do GE e GM, as principais considerações podem ser vistas no Quadro 2.

Quadro 2. Ações de ID do GE e do GM na perspectiva da educação

Ações do GE ligadas à política educacional, Banda Larga nas Escolas, Prouca, ProInfo Integrado

O GE evidenciou os papeis dos demais atores sociais nos processos de ID: a responsabilidade das empresas; a influência dos professores na construção de propostas que iriam além da técnica pura, voltadas à reflexão sobre a inserção das tecnologias nos processos humanos.

O GE apresentou um plano de educação abrangente, com ações em diversos eixos, valorizando cultura e cidadania, e a ID enquanto um eixo a ser integrado aos demais. Na gestão participativa, as ações trouxeram as comunidades escolar e local para as escolas e para os debates no Orçamento Democrático, sugerindo fala e escuta ativas, integração social e melhoria de serviços através do conhecimento advindo dos contextos locais.

Nas escolas de tempo integral, as oficinas foram ações importantes: aquela de "cultura digital", enquanto base para debate e ação, uma vez que a sociedade apresenta "culturas digitais", que convivem no ambiente técnico, dialogando com elementos locais; aquela de "educomunicação", a partir dos elementos motivacionais quanto 
VII Congresso Brasileiro de Informática na Educação (CBIE 2018)

Anais do XXIV Workshop de Informática na Escola (WIE 2018)

ao seu uso em contextos próprios, a partir dos temas geradores comunitários, assim como no estudo no IFPB.

O GE realizou eventos para discutir as boas práticas para a ID (inclusive na educação), e os eventos tiveram transmissão online, alargando a "inclusão" e chegando a interessados no mundo físico ou virtual.

Sobre os beneficiários das ações, os seus discursos, quanto às práticas de gestão compartilhada, sugeriram a aproximação dos atores sociais, ampliando o sentimento de inclusão, importante em contextos de escolas públicas. Aproximando-se de diretores, professores e alunos de escolas públicas, no estudo no IFPB, os pesquisadores entenderam a complexidade de lidar com problemas em estrutura, aspectos humanos, contextos comunitários. Nesses cenários, a gestão em parceria com interessados foi importante para realizar processos educacionais próprios e efetivos. As tecnologias potencializam mudanças, a partir das possibilidades de integração, comunicação entre diversos atores sociais, para decisões e ações de interesse público.

\section{Acões do GM ligadas à política educacional, Banda Larga nas Escolas, Prouca, ProInfo Integrado}

O GM investiu nas escolas implantando sistemas, adquirindo tecnologias, qualificando profissionais de forma continuada, em virtude da "necessidade" de adequação das escolas às "novas exigências sociais e tecnológicas". Era preciso trabalhar a política pública de forma transversal, inserindo a ID em um contexto maior, com o objetivo de disponibilizar TDIC para melhorar o ensino público: a capacitação foi feita de forma continuada, acompanhando a dinamicidade das TDIC como instrumentos pedagógicos; a entrega dos computadores simbolizou o compromisso do educador com as novas propostas pedagógicas; a robótica foi usada enquanto elemento que exercia fascínio entre crianças, jovens e adultos. As qualificações dos profissionais de educação tinham duplo significado: beneficiar esses profissionais em seus processos de ID; transformá-los em agentes ativos na ID de alunos e comunidades em geral, em ações nas escolas públicas.

O GM abriu as escolas em turnos opostos e finais de semana, com atividades voltadas à comunidade escolar, mas também às comunidades no entorno da escola, potencializando a apropriação dos seus espaços enquanto lugar público e a ampliação de sentimento de pertencimento a grupos sociais mais amplos.

O GM sugeriu uso multidisciplinar das TDIC, o que potencializa suas ações, e ofertou essas tecnologias como condição de igualdade entre alunos da rede municipal e aqueles das demais escolas públicas ou privadas.

Os debates em torno da relação entre educação e TDIC, em eventos públicos, compartilharam conhecimento e experiências em perspectivas diversas, como aspectos pedagógicos, cidadania e desenvolvimento humano.

Nas escolas de tempo integral, a transversalidade das oficinas se mostrou importante, sugerindo que a ID pode ser trabalhada de forma contextualizada, a partir da relação entre TDIC e outros macrocampos ou conteúdos trabalhados em sala de aula. Entre seus temas estavam a educomunicação e a ID. A experiência no IFPB apresentou formas de trabalhar essas áreas visando à promoção da cidadania e à inclusão social (fazendo uso das mídias digitais com foco nos temas geradores nas comunidades), o que foi considerado um caso de sucesso no caminho para efetividade de uso das TDIC em ambientes escolares e comunitários.

Quanto aos beneficiários das ações, a escola integral representou uma mudança nas vidas dos alunos, dando sentido ao "tempo livre", estimulando a busca pelo conhecimento e o desenvolvimento de novas práticas sociais. Em geral, as TDIC representaram mudanças "significativas" nas práticas educativas dos professores e monitores, motivação dos alunos para as aulas e melhores resultados em aprendizagem.

\section{Ações do GE e do GM}

Em 2010, 56\% das escolas públicas do Brasil estavam conectadas à internet. Na Paraíba, esse número chegou a 95\%, sendo metade delas em João Pessoa (ambas ficaram acima da média nacional).

O GE e o GM desenvolveram ações de EAD, acreditando que o uso das plataformas digitais trazia, entre seus benefícios, a ampliação e a diversificação do número de pessoas atendidas em ações de qualificação.

As sociedades contemporâneas cresceram, especializaram-se e se complexificaram, e então novos modelos são propostos para acompanhar essas transformações, a dar suporte às novas estruturas de geração e transmissão de conhecimento. As tecnologias permitem a criação de um repositório virtual de conceitos, conteúdos e experiências que traduzem a vida humana, sob perspectivas diversas e próprias, compondo um conjunto de saberes, contribuindo para a inteligência coletiva, enquanto processo principalmente cognitivo. A geração do conhecimento e o acesso a este envolvem redefinições sociais que questionam papeis (professor e aluno) e processos educacionais tradicionais. Nesse sentido, os governos propuseram ensino e qualificação que valorizassem o contato com comunidades, culturas e conhecimentos particulares. Foram ainda desenvolvidas ações de qualificação de professores, alunos, monitores de espaços públicos (chamados "educadores sociodigitais"), voltadas não apenas às habilidades em TDIC, mas ao "pensar o social", seus contextos, problemas e soluções, e a colocar as TDIC como elementos desses processos, e não o centro deles. De algumas formas, as pessoas foram empoderadas e o reconhecimento das 
VII Congresso Brasileiro de Informática na Educação (CBIE 2018)

Anais do XXIV Workshop de Informática na Escola (WIE 2018)

mudanças pode ser visto em seus discursos. A mudança social se deu, em parte, de acordo com as experiências de uso ou apropriação das TDIC, como os diversos atores sociais foram integrados ou não, a partir de suas visões de mundo.

No IFPB, outras análises sobre os aspectos de educação digital para uso de TDIC com vistas à cidadania e à inclusão social foram desenvolvidas. Historicamente falando, as ações de ID no IFPB foram influenciadas pelo GF, GE e GM, sendo identificadas parcerias entre os três níveis de governos e o IFPB, em diversos momentos, entre 2007 e 2017: o IFPB participou de programas e projetos nacionais; o IFPB executou ações pontuais como oferta de qualificação em TDIC para grupos sociais específicos, em parceria com GE ou GM, influenciando o sentido das ações junto aos governos, nos cursos de qualificação. No IFPB, os processos de qualificação foram ou experiências educacionais "tradicionais", no programa $\mathrm{P} 1$, oferecendo cursos prontos e fechados (não incluíram as pessoas em seus processos de construção e não dialogaram com condições reais de existência), ou outras mais contemporâneas, no programa P2, sendo repensadas continuamente, através de ideias inovadoras. Nas ações tradicionais, o processo de ID de uma comunidade foi interrompido, já que esta não conseguiu protagonizá-lo, o que representou uma frustração para o P1, e para a rede estabelecida em torno dessa comunidade. Em geral, as turmas no P1 apresentaram sentimentos de desencanto porque as pessoas queriam desenvolver ações complementares, mas a proposta pedagógica se limitou às aulas e o programa não se abriu para repensá-la. As ações contemporâneas, por sua vez, realizaram processos diferentes, indo às comunidades e trabalhando em parcerias com elas, pois ações "prontas e padronizadas" eram uma lacuna na definição da extensão. Essa ideia foi sustentada por evidências de projetos já implementados (inclusive fracassos) e sugestões da nova política de extensão, que alargava o espaço da cidadania, inclusive a partir das TDIC.

A valorização da quebra dos centros de referência, do conhecimento aberto, das vozes locais, da desterritorialização das ações, das relações horizontais, foram elementos de trabalho no IFPB, no novo paradigma de extensão e nos seus pressupostos para construir uma cultura de olhar além das suas fronteiras, de ver o outro como uma fonte legítima de aprendizagem, através de relações construídas sobre confiança e respeito, sem prazo de validade e com fluxos bidirecionais de crescimento técnico e humano. Nas sociedades modernas, as zonas de significação são móveis e os processos de inteligência coletiva não se confundem com "formação" ou "erudição", mas com o valor do conhecimento no contexto em que se está inserido.

Sobre o sentido da cidadania e da inclusão social através da extensão, foram evidenciados alguns cenários: no P1, algumas pessoas já se sentiam incluídas (embora buscassem mais qualificação), entretanto, a maioria se sentia excluída digital e/ou socialmente, e associava, ao IFPB, novas possibilidades de qualificação para trabalho, integração em escopos sociais maiores, autodesenvolvimento para uma cidadania mais ampla; no P2, em sua maioria, as pessoas se sentiram excluídas digital e socialmente, pela ineficiência e/ou ausência dos artefatos e/ou processos de ID e pela falta de oportunidades sociais ou acesso a bens de direito. Para os "excluídos", o "fim" das ações do IFPB parecia uma interrupção em projetos de vida, fossem em ID, ou em cidadania. Em seus espaços, sempre faltava algo, pedia-se mais, ou infraestrutura, ou qualificação, o que evidenciou que o processo de ID para inclusão social e cidadania é complexo e requer políticas multidimensionais e contínuas, em médio ou longo prazo.

Apesar desses problemas, P1 e P2 deixaram contribuições importantes para as comunidades e grupos atendidos, a partir de suas perspectivas próprias de inclusão. No 
VII Congresso Brasileiro de Informática na Educação (CBIE 2018)

Anais do XXIV Workshop de Informática na Escola (WIE 2018)

P1, através dos cursos que de alguma forma aproximaram as pessoas das TDIC. No P2, em alguns territórios de ação, os níveis de pobreza, de demandas diversas, eram tão grandes que as TDIC poderiam não ter significados evidentes. Entretanto, essas tecnologias foram trabalhadas enquanto motivação para pensar aspectos naturalizados, mas que requeriam mudanças em ações das comunidades ou do poder público, como a limpeza dos rios, a violência no entorno comunitário, a integração das comunidades rurais, temas importantes para a esfera pública. Em uma escola pública, às estratégias de ensino já desenvolvidas pelos professores foram somadas novas propostas de atividades em TDIC (por exemplo, o estudo das condições ambientais com aulas de campo, fotografias, filmagens, "aulas vivas"), o que foi considerado mais efetivo do que aulas tradicionais. Nessa escola, os trabalhos sociais já faziam parte dos projetos pedagógicos, tomando dimensões maiores, depois que o P2 apresentou a educomunicação e recursos dos smartphones a alunos e professores.

A vivência no campo evidenciou a importância do conhecimento acadêmico e do popular, dos temas transversais que contextualizavam o empírico, nos processos de aproximação entre pessoas e TDIC. Embora a efetividade dos aspectos educacionais se relacione de forma direta à efetividade da ID, outras dimensões também são importantes para processos de inclusão. Por utilizar o espaço do IFPB nas suas ações, o P1 não foi diretamente afetado pela política pública de ID. Uma vez que as ações do P2 se deram em territórios de escolas e comunidades, este vivenciou, junto a parceiros, a desproteção por parte do Estado com relação às TDIC (carência de professor de informática, infraestrutura e técnicos em TDIC, entre outros).

\section{Conclusões}

O reconhecimento da importância das TDIC para o desenvolvimento das sociedades, aliado à pressão para que o mundo seja incluído digitalmente, tem acelerado a reflexão sobre ações e resultados em ID. Embora a ID tenha um discurso voltado a todos, suas ações só são desenvolvidas onde chegam infraestrutura física e lógica, e conhecimento sobre como fazer uso desses recursos em prol de uma vida melhor.

No Brasil, a ID é uma reivindicação social, e embora esteja associada à cidadania e à inclusão, não está disponível para todos, não se realiza plenamente. A política pública de ID promove a cidadania e inclusão, à medida que realiza expectativas da sociedade, entre elas, favorece novas perspectivas de trabalho, educação e comunicação, discute com diversos atores sociais os seus ciclos de ação, desenvolve ações mutidimensionais e específicas em contextos, aproxima, de alguma forma, as pessoas das TDIC. Entretanto, essa realização se dá em passos lentos e apresenta problemas de efetividade. Nesse contexto, a exclusão persiste, em uma lógica que reflete as desigualdades ou ausências do mundo físico, também no virtual, em várias perspectivas (como econômica, rural/urbano, gênero, etnias). Enfim, os processos de ID no Brasil estão caminhando, o lugar ocupado pelos "antes excluídos" mudou, de alguma forma, levando-os a se perceber/ser percebidos como "mais cidadãos", pois alguns sentidos de cidadania e inclusão estão se realizando (ser reconhecido pelo Estado, que destina atenção aos seus problemas; estar conectado à rede mundial e construir relações e ações, entre outros).

No IFPB, as ações sugeriram, principalmente, a importância de pensar a ID e seus processos através de diálogo entre as partes interessadas, contrariando a ideia de realizar ações "para outros", ainda vista como uma base para fazer extensão, nesta 
VII Congresso Brasileiro de Informática na Educação (CBIE 2018)

Anais do XXIV Workshop de Informática na Escola (WIE 2018)

instituição, e fazer políticas públicas, no Brasil. A ID deve contar com processos educacionais que promovam a competência informacional e a inteligência coletiva, imprescindíveis aos processos participativos e democráticos idealizados pela sociedade em rede. Ações educacionais para autodesenvolvimento, conscientização e libertação, como a qualificação contextualizada, são vistas como a ampliação do sentido das TDIC.

Referente às dificuldades da pesquisa, não foi fácil trabalhar nos portais, pois as ações de ID se capilarizaram, penetrando espaços e sendo penetradas por várias políticas públicas. Outras dificuldades foram: divergências entre GE e GM e ausência ou insuficiência da política de ID limitaram ações em territórios comunitários e escolas públicas; no IFPB, cortes financeiros inviabilizaram ações e intervenções geraram desgaste em relações. Como trabalhos futuros, será continuada a análise dos dados.

\section{Referências}

Brasil. (2015) Tribunal de Contas da União. Política pública de inclusão digital / Tribunal de Contas da União. - Brasília: TCU, SeinfraAeroTelecom.

Capra, F. (2008) "Vivendo redes”. In: O tempo das redes. São Paulo: Perspectivas.

Castells, M. (2000) A Sociedade em Rede. São Paulo: Paz e Terra.

Corrêa, R.A.A. (2007) Construção Social dos Programas Públicos de Inclusão Digital. Brasília: Universidade de Brasília. 168 f. Dissertação (Mestrado em Sociologia).

Ferreira, A.C. (2016) Junho de 2013: hiperetnografia de uma insurreição "invisível". 30a . Reunião Brasileira de Antropologia, UFPB, João Pessoa.

Foote-Whyte, W. (2005) Sociedade de esquina. Rio de Janeiro: Editora Zahar.

Giddens, A. (1991) As consequências da modernidade. São Paulo: Editora Unesp.

Latour, B. (2011) Networks, Societies, Spheres: Reflections of an Actor-Network Theorist. International Journal of Communication.

Lévy, P. (1999) Cibercultura. Tradução de Carlos Irineu da Costa. São Paulo: Ed. 34.

Martino, L.M.S. (2015) Teoria das Mídias Digitais. Petrópolis, RJ: Vozes.

Mattos, F.A.M.; Chagas, G.J.N. (2008) Desafios para a inclusão digital no Brasil. Perspectivas em Ciência da Informação, v. 13, n. 1, 67-94, jan.-abr.

Medeiros Neto, B.; Miranda, A.L.C. (2010) Uso da tecnologia e acesso à informação pelos usuários do programa Gesac e de ações de inclusão digital do governo brasileiro. Universidade de Brasília. Brasília, DF, v. 3, n. 2, p.81-96, jan./jun.

Perlongher, N. (2008) O Negócio do Michê. São Paulo: Perseu Abramo.

Queiróz, M. I. P. (1998) 'Relatos orais: do 'indizível' ao 'dizível'”. In: Von S., Olga M., Experimentos com Histórias de Visa. SP: Vértice, Editora dos Tribunais, pp. 14-43.

Rodrigues, A.V.; Maculan, A. M. D. (2013) Indicadores de Inclusão Digital. TIC Domicílios e Empresas 2012. São Paulo: CETIC.BR.

Rodrigues, N.N. et al. (2011) Tecnologias de Informação e Comunicação Aplicadas à Terceira Idade. Workshop de Informática na Escola, Aracajú.

Santiago, L.B.M. et al. (2016) O uso das Tecnologias Digitais na busca da superação do analfabetismo. Congresso Brasileiro de Informática na Educação, Uberlândia. 